\title{
Investigation of glucocorticoid-induced apoptotic pathway: Processing of Caspase- 6 but not Caspase-3
}

\author{
Toshiyuki Miyashita ${ }^{1,4}$, Kazuaki Nagao,,2, \\ Stanislaw Krajewski ${ }^{3}$, Guy S. Salvesen ${ }^{3}$, John C. Reed ${ }^{3}$, \\ Tadashi Inoue $^{2}$ and Masao Yamada ${ }^{1}$ \\ ${ }^{1}$ Department of Genetics, National Children's Medical Research Center, Tokyo \\ 154, Japan \\ ${ }^{2}$ College of Biological Resource Sciences, Nihon University, Fujisawa, \\ Kanagawa 252, Japan \\ 3 The Burnham Institute, 10901 N. Torrey Pines Road, La Jolla, CA 92037, USA \\ ${ }^{4}$ corresponding author: Toshiyuki Miyashita, Department of Genetics, National \\ Children's Medical Research Center, 3-35-31 Taishido, Setagayaku, Tokyo \\ 154, Japan. tel: +81-3-3414-8121; fax: +81-3-3414-3208; \\ e-mail: tmiyashita@nch.go.jp
}

Received 20.4.98; revised 8.6.98; accepted 15.7.98

Edited by D.R. Green

\begin{abstract}
Glucocorticoids (GCs) are essential therapeutic reagents for the treatment of lymphomas and leukemias. GCs cause cell death in certain types of lymphoid cells mediated by the process known as apoptosis. This cell death is completely inhibited by Bcl-2. Here we report that Bcl-2 and benzyloxycarbonyl-Val-Ala-Asp(OMe)-fluoromethylketone (zVAD$\mathrm{fmk}$ ), a broad spectrum caspase inhibitor, prevent loss of mitochondrial membrane potential $(\Delta \Psi \mathrm{m})$ and the production of reactive oxygen species (ROS) caused by GC, while acetylAsp-Glu-Val-Asp-aldehyde (Ac-DEVD-CHO), an inhibitor of the caspase- 3 family proteases, does not. This suggests that the inhibition by $\mathrm{Bcl}-2$ and activation of some initiator caspases are upstream events of mitochondrial damage, whereas the activation of caspase- 3 family proteases occurs downstream of mitochondrial changes. We also demonstrate that caspase- 6 but not caspase- 3 is cleaved and activated during GC-mediated apoptosis and that poly(ADP-ribose) polymerase (PARP), a substrate of caspases, also undergoes proteolysis. In addition, we provide the evidence that DNA fragmentation is markedly inhibited by Ac-DEVD-CHO, while cell death, assessed by the damage of the plasma membrane, is marginally inhibited or merely delayed.
\end{abstract}

Keywords: apoptosis; glucocorticoid; $\mathrm{Bcl}-2$; caspase family

Abbreviations: GC, glucocorticoid; DEX, dexamethasone; ROS, reactive oxygen species; PARP, poly(ADP-ribose) polymerase; PI, propidium iodide; $\Delta \Psi \mathrm{m}$, mitochondrial transmembrane potential; $\mathrm{DiOC}_{6}(3), 3,3^{\prime}$-dihexyloxacarbocyanine iodide; DCFH-DA, 6carboxy-2', 7'-dichlorodihydrofluorescein diacetate, di(acetoxymethyl ester); Ac-DEVD-CHO, acetyl-Asp-Glu-Val-
Asp-aldehyde; Ac-VEID-MCA, acetyl-Val-Glu-Ile-Asp-methylcoumarylamide; zVAD-fmk, benzyloxycarbonyl-Val-AlaAsp(OMe)-fluoromethylketone; DMSO, dimethyl sulfoxide

\section{Introduction}

Programmed cell death also called apoptosis is an essential mechanism to remove superfluous or damaged cells during the development and maintenance of multicellular organisms. It is also well-known that chemotherapeutic drugs including glucocorticoids (GCs) kill tumor cells through an apoptotic mechanism. The Bcl-2 and caspase families of proteins have been identified as regulators and effectors of apoptosis, respectively. We previously reported that overexpression of $\mathrm{Bcl}-2$ in leukemic cells completely inhibits GC-induced apoptosis and relieves the transrepressive function of glucocorticoid receptor (Miyashita and Reed, 1993; Miyashita et al, 1997). However, the precise mechanism of how GC mediates apoptosis is yet to be elucidated.

Recently mitochondrial damage, observed as a disruption of the mitochondrial transmembrane potential $(\Delta \Psi \mathrm{m})$ or an increase in reactive oxygen species (ROS) generation has been recognized as a cell death commitment step in the course of apoptosis induced by many stimuli. In recent years, evidence has accumulated that these mitochondrial alterations involve opening of the so-called permeability transition (PT) pore (Kroemer et al, 1997).

The ICE-like cysteine proteases or caspases play important roles in apoptosis. To date, more than ten family members have been identified and classified into two groups, initiators and effectors (Salvesen and Dixit, 1997). Caspase-3 (Yama/CPP32/apopain) (Tewari et al, 1995; Fernandes-Alnemri et al, 1994; Nicholson et al, 1995), one of the effector caspases, has been studied extensively using specific antibodies, inhibitors and fluorogenic substrates. Caspase-3-like proteases are activated during most apoptotic processes. Caspases are synthesized as zymogens and become activated by proteolytic processing at specific aspartic acid residues, resulting typically in the removal of an $\mathrm{N}$-terminal prodomain and another cleavage event which produces the large and small subunits that comprise the active heterotetrameric protease. This processing and activation of caspases can be mediated either by themselves or by other caspases (Salvesen and Dixit, 1997). The ability of caspases to cleave each other has suggested the existence of proteolytic cascades. However, the specific caspases involved and their relative order appears to vary widely depending on the cellular background and apoptotic stimulus.

Here we demonstrate the sequence of events that occur in GC-mediated apoptosis of a pre B-cell leukemia cell line and provide new insights into caspase cascades. 


\section{Results}

\section{Bcl-2 inhibits GC-induced loss of $\Delta \Psi \mathrm{m}$ and generation of reactive oxygen species}

To determine whether Bcl-2 exerts its anti-apoptotic activity upstream or downstream of mitochondrial changes associated with GC-induced apoptosis, we overexpressed Bcl-2 in the human pre-B leukemia cell line 697 which is highly sensitive to GC. Previously reports indicated that Bcl-2 can completely inhibit GC-mediated cell death of 697 cells (Miyashita and Reed, 1993). We utilized the membrane potential-sensitive carbocyanine probe, 3, 3'-dihexyloxacarbocyanine iodide $\left(\mathrm{DiOC}_{6}(3)\right)$ to detect $\Delta \Psi \mathrm{m}$ and 6-carboxy-2', 7'-dichlorodihydrofluorescein diacetate, di(acetoxymethyl ester) (DCFH-DA) to assess intracellular oxidation (Petit et al, 1990; Hockenbery et al, 1993). DCFH-DA is oxidized to a fluorogenic dye by reactive oxygen species (ROS) in cells. As shown in Figure 1A, treatment of control transfected $697-\mathrm{Neo}$ cells with the synthetic GC, dexamethasone (DEX), decreased the percentage of cells with intact $\Delta \Psi \mathrm{m}$, whereas loss of $\Delta \Psi \mathrm{m}$ was completely inhibited in 697-Bcl-2 cells. Overexpression of Bcl2 also completely inhibited DEX-induced ROS production. Note that ROS generation was slower than loss of $\Delta \Psi \mathrm{m}$ in DEX-treated 697-Neo cells (Figure 1B). ROS generation was not observed at $24 \mathrm{~h}$, for example, whereas $\Delta \Psi \mathrm{m}$ loss was evident at $16 \mathrm{~h}$ after the DEX treatment.

\section{zVAD-fmk but not Ac-DEVD-CHO prevents ROS production and loss of $\Delta \Psi \mathrm{m}$}

Since we previously demonstrated that caspase-3-like proteases were activated during GC-mediated apoptosis (Miyashita et al, 1997), we further investigated the relationship between the caspase activation and mitochondrial changes. In contrast to $\mathrm{Bcl}-2$ overexpression, inhibition of caspase-3-like proteases by acetyl-Asp-Glu-Val-Asp-aldehyde (Ac-DEVD$\mathrm{CHO}$ ) did not block the loss of $\triangle \Psi \mathrm{m}$ or ROS production (Figure $2 \mathrm{~A}$ and $2 \mathrm{~B}$ ). The addition of Ac-DEVD-CHO into the culture medium, however, completely inhibited the activation of caspase-3-like proteases in DEX-treated 697-Neo cells as determined by a fluorogenic assay for DEVD-cleaving proteases. The inhibition was as efficient as that achieved by the overexpression of $\mathrm{Bcl}-2$ (Figure $2 \mathrm{C}$ ). Thus, the intracellular concentration of Ac-DEVD-CHO is high enough to prevent caspase-3 activation. In contrast, benzyloxycarbonyl-Val-AlaAsp(OMe)-fluoromethylketone (zVAD-fmk), a caspase inhibitor of broad specificity efficiently prevented the loss of $\Delta \Psi \mathrm{m}$ and ROS production (Figure $2 \mathrm{~A}$ and $2 \mathrm{~B}$ ). These results indicate that, unlike caspase-3-like proteases, some caspases inhibited by zVAD-fmk but not by Ac-DEVD-CHO are activated upstream of mitochondrial damages.

\section{Caspase-3-like proteases other than caspase-3 itself is involved in GC-mediated apoptosis}

We next examined if caspase-3 became activated during GCmediated apoptosis. A potential substrate of caspase-3, poly(ADP-ribose) polymerase (PARP), was indeed cleaved after treatment of 697-Neo cells with DEX. Again, Bcl-2 completely blocked PARP cleavage (Figure 3A). However, no

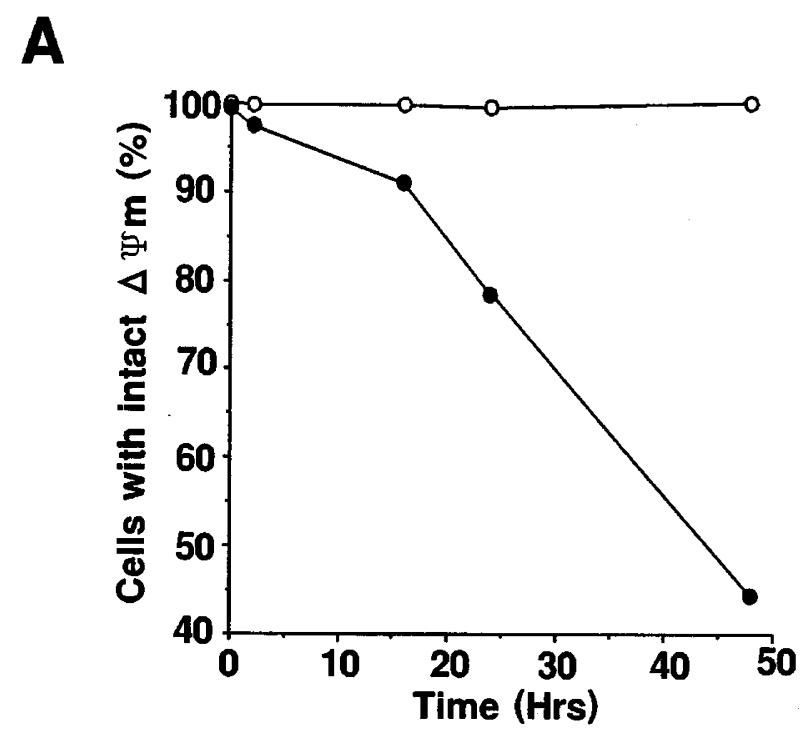

B

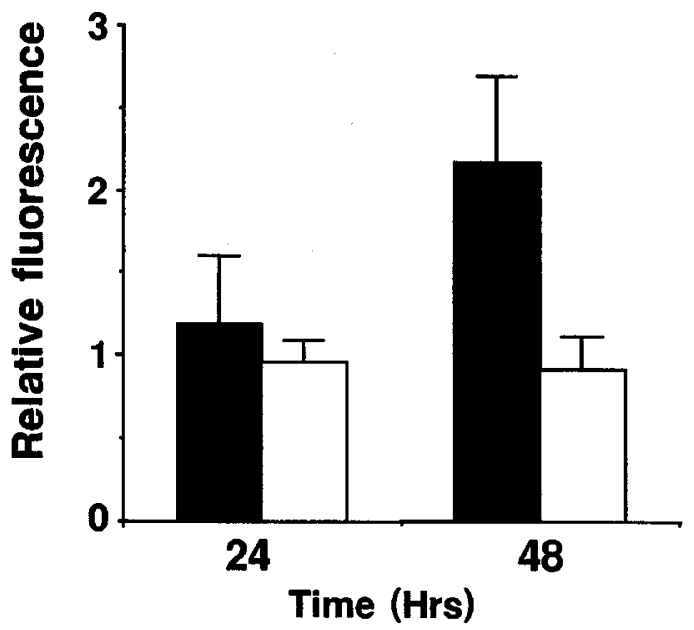

Figure $1 \mathrm{Bcl}-2$ prevents DEX-induced ROS production and loss of $\Delta \Psi \mathrm{m}$. (A) 697-Neo cells (closed circles) and 697-Bcl-2 cells (open circles) were treated with $10^{-7} \mathrm{M}$ of DEX. At various time points, cells were harvested, stained with $\mathrm{DiOC}_{6}(3)$ and subjected to flow cytometry. (B) 697-Neo cells (closed boxes) and $697-\mathrm{Bcl}-2$ cells (open boxes) were treated with $10^{-7} \mathrm{M}$ of DEX. At indicated time points, cells were stained with DCFH-DA and subjected to flow cytometry. Fluorescent intensity relative to that obtained before DEXtreatment was represented. All data represent mean $(n=3)$; bars, S.D.

cleavage of caspase-3 was detected by immunoblot analysis of DEX-treated 697-Neo cells or 697-Bcl-2 cells (Figure 3B). Processed form of caspase- 3 was not visualized even after the longer exposure of an X-ray film. Since caspases are synthesized as zymogens and proteolytically activated, we concluded that caspase-3-like proteases other than caspase3 itself is activated in GC-mediated apoptosis. The validity of our immunoblotting assay was supported by analysis of lysates from 697-Neo cells which had been induced to undergo etoposide-mediated apoptosis. Using the same anti-caspase-3 antibody, procaspase-3 was cleaved and processed into its active form after $6 \mathrm{~h}$ of treatment with etoposide (Figure 3C). 
A

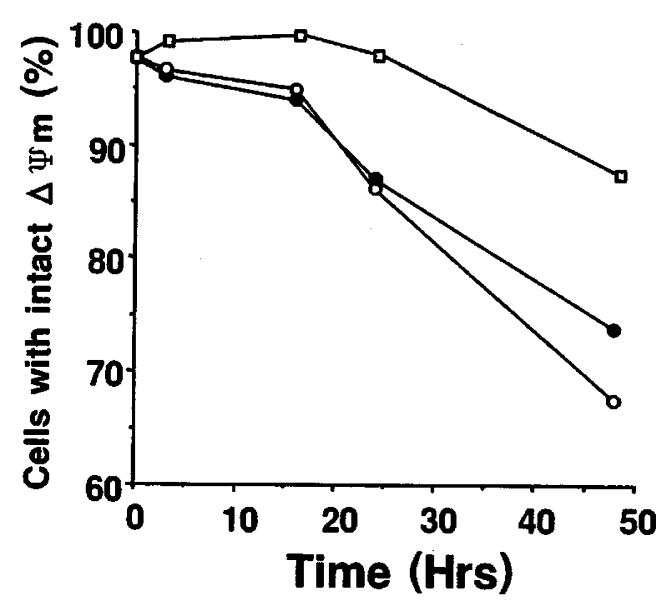

B
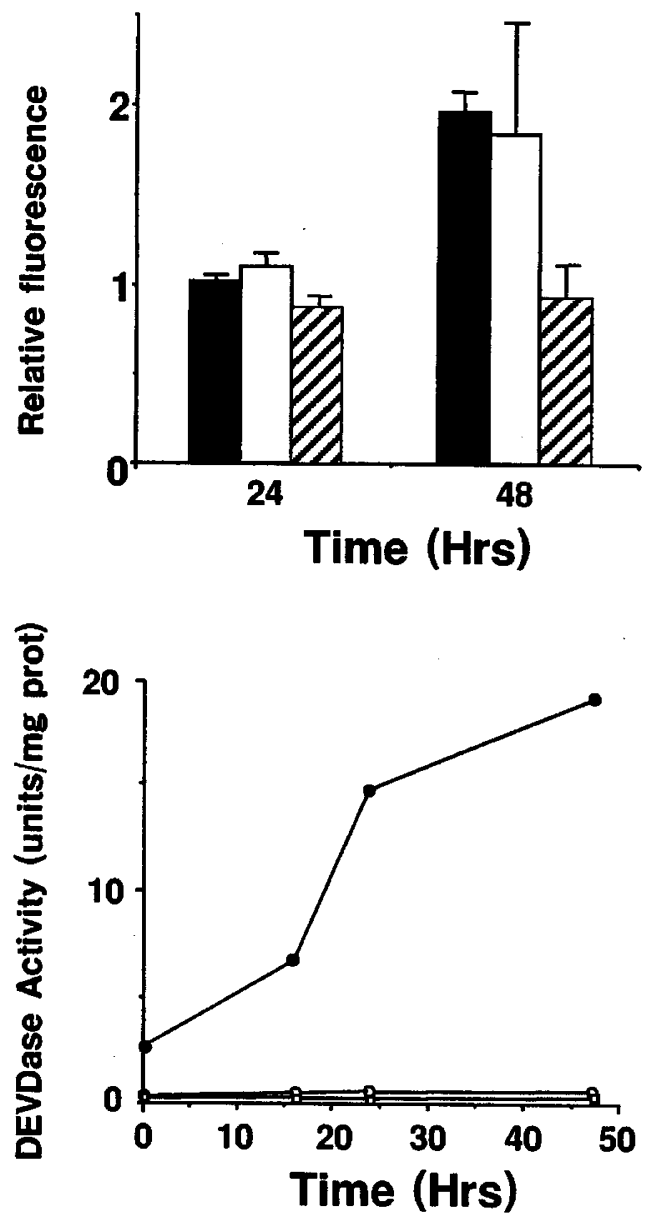

Figure 2 zVAD-fmk but not Ac-DEVD-CHO inhibits ROS production and loss of $\Delta \Psi \mathrm{m}$. (A) $697-\mathrm{Neo}$ cells were treated with $10^{-7} \mathrm{M}$ of DEX in the presence of DMSO (closed circles), $100 \mu \mathrm{M}$ of Ac-DEVD-CHO (open circles) or $100 \mu \mathrm{M}$ of zVAD-fmk (open squares). At various time points, cells were harvested, stained with $\mathrm{DiOC}_{6}(3)$ and subjected to flow cytometry. DMSO was used as a vehicle control. (B) $697-\mathrm{Neo}$ cells were treated with $10^{-7} \mathrm{M}$ of DEX in the presence of DMSO (closed boxes), $100 \mu \mathrm{M}$ of Ac-DEVD-CHO (open boxes) or $100 \mu \mathrm{M}$ of zVAD-fmk (hatched boxes). At indicated time points, cells were stained with DCFH-DA and subjected to flow cytometry. Fluorescent intensity relative to that obtained before DEX-treatment was represented. All data represent mean $(n=3)$; bars, S.D. (C) Cytosolic extracts were prepared from 697-Neo cells and 697-Bcl-2 cells (open squares) which were grown with

\section{Caspase- 6 is activated during GC-mediated apoptosis}

To explore which caspases are activated during GC-mediated apoptosis, we next analyzed the cleavage of caspase- 6 (Mch2) (Fernandes-Alnemri et al, 1995a) and caspase-8 (FLICE/MACH/Mch5) (Muzio et al, 1996; Boldin et al, 1996; Fernandes-Alnemri et al, 1996). We detected two isoforms of caspase-8, which have recently been reported as caspase-8/ a and caspase-8/b (Scaffidi et al, 1997), in the 697 cells. Although caspase-8 has also been shown to cleave PARP in vitro (Muzio et al, 1996), cleavage of caspase-8 was not detected in GC-treated 697 cells throughout the time period examined (Figure 4A). This same antibody did detect processed caspase- 8 in anti-Fas treated Jurkat cells (not shown). In contrast, the levels of procaspase-6, one of the other effector caspases, gradually decreased following treatment of $697-\mathrm{Neo}$ cells with DEX, accompanied by the detection of the processed form of caspase- 6 after $24 \mathrm{~h}$ of the treatment (Figure 4B, upper panels). The time course of procaspase- 6 cleavage was almost identical with that of PARP. Cleavage of procaspase- 6 was again inhibited by the overexpression of Bcl-2 (Figure 4B, lower panels). To confirm the activation of caspase-6, we used caspase-6-specific substrate, acetyl-Val-Glu-Ile-Asp-methylcoumarylamide (AcVEID-MCA) (Hirata et al, 1998), and performed fluorometric measurement of caspase- 6 activities. In 697-Neo cells but not in $697-\mathrm{Bcl}-2$ cells, caspase- 6 activities increased after the treatment with DEX showing the similar kinetics as immunoblot analysis (Figure $4 \mathrm{C}$ ).

\section{Inhibition of caspase-3-like proteases inhibits DNA fragmentation but not DEX-induced cell death}

Previously, we have shown that Ac-DEVD-CHO only partially blocked DEX-induced cell death as determined by trypan blue dye exclusion (Miyashita et al, 1997). In this study, we examined the effect of this caspase inhibitor on DNA fragmentation which is one of the hallmarks of apoptosis. As anticipated from the previous work, Ac-DEVD-CHO delayed the loss of membrane integrity but did not prevent cell death determined by monitoring the ability of cells to exclude propidium iodide (PI) (Figure 5A). In contrast, DNA fragmentation was markedly inhibited by Ac-DEVD-CHO. Even after $48 \mathrm{~h}$ of DEX treatment very little DNA fragmentation was observed in cells cultured with Ac-DEVD-CHO (Figure 5B). Marked inhibition of PARP cleavage in DEX-treated 697 cells again indicates that the permeability of Ac-DEVD-CHO is high enough to prevent intracellular activation of caspase-3-like proteases (compare Figure 5C with Figure 3A). However, zVAD-fmk again significantly blocked both cell death and DNA fragmentation (Figure 5A and data not shown).

$10^{-7} \mathrm{M}$ of DEX for various times. 697-Neo cells were grown in the presence of DMSO (closed circles) or $100 \mu \mathrm{M}$ of Ac-DEVD-CHO (open circles). DEVDspecific caspase activities were measured using a fluorescent substrate AcDEVD-MCA. One unit corresponds to the activity that cleaves $1 \mathrm{nmol}$ of the substrate at $37^{\circ} \mathrm{C}$ in $2 \mathrm{~h}$ 


\section{Discussion}

The hallmarks of apoptosis such as chromatin condensation or nuclear and DNA fragmentation are reported to be preceded by alterations in mitochondria (Kroemer et al, 1997). We have confirmed the loss of $\Delta \Psi \mathrm{m}$ and production of ROS during GC-mediated apoptosis. $\Delta \Psi \mathrm{m}$ reduction was an earlier event than ROS generation which is in agreement with previous reports suggesting sequential reduction of $\Delta \Psi \mathrm{m}$ followed by generation of ROS (Zamzami et al, 1995). However, in our system, detectable ROS generation was even later than DNA fragmentation or the loss of membrane integrity.

In our cellular system, zVAD markedly inhibited the loss of $\Delta \Psi \mathrm{m}$ and production of ROS mediated by GC. In contrast, Ac-DEVD-CHO, an inhibitor of the caspase-3
A
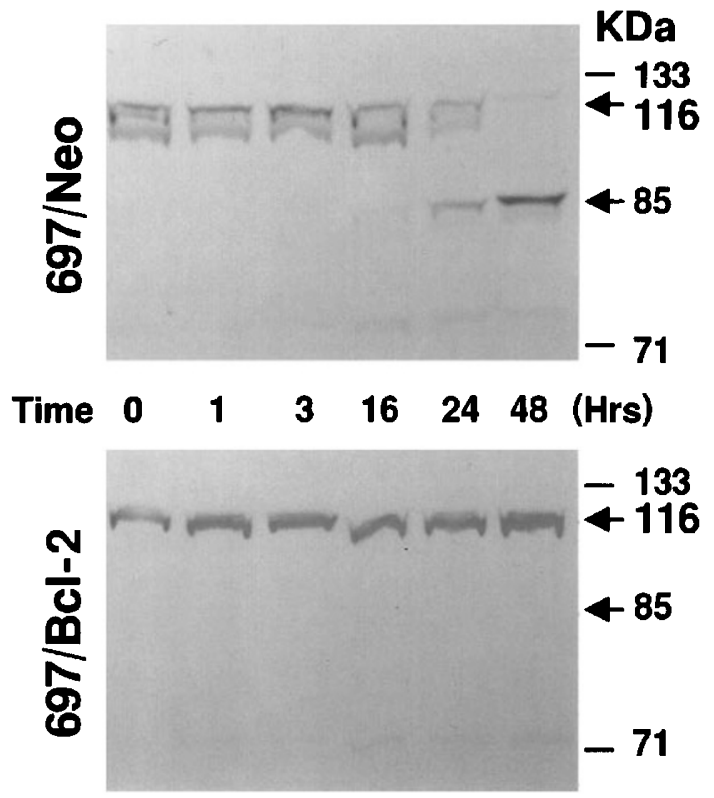

$\mathrm{KDa}$

48.9

$-32$

24.4

$-17.4$

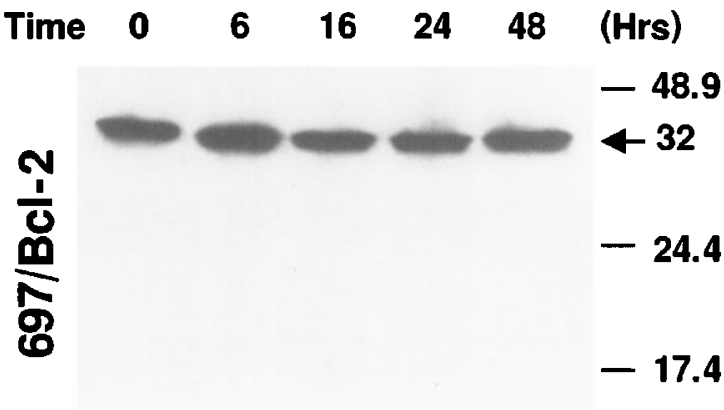

C

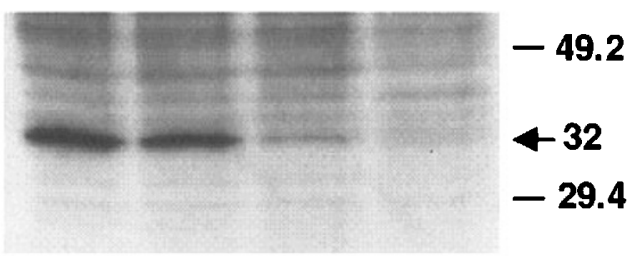

$\begin{array}{llllll}\text { Time } & 0 & 3 & 6 & 16 & \text { (Hrs) }\end{array}$

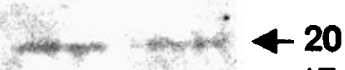

$-17.4$

Figure 3 Absence of caspase-3 processing during GC-induced apoptosis. (A and B) $697-\mathrm{Neo}$ cells or $697-\mathrm{Bcl}-2$ cells were treated with $10^{-7} \mathrm{M}$ of DEX. At various time points, cells were harvested and cell lysates were subjected to SDS-PAGE, transferred to nitrocellulose and probed with anti-PARP (A) or anti-caspase-3 (B) antibodies. (C) $697-\mathrm{Neo}$ cells were treated with $70 \mu \mathrm{M}$ of etoposide. At indicated time points, cell lysates were obtained and subjected to SDS - PAGE, transferred to nitrocellulose and probed with anti-caspase-3 antibody. Arrows indicate full length PARP (p116), processed PARP (p85), procaspase-3 (p32), and processed caspase-3 (p20) 
family proteases, did not block mitochondrial alterations. Recent reports indicated that zVAD-fmk and Ac-YVAD$\mathrm{CHO}$, an inhibitor of the caspase-1 family proteases, prevent the loss of $\Delta \Psi \mathrm{m}$ in UVB-mediated and anti-Fas mediated apoptosis, respectively (Bossy-Wetzel et al, 1998; Susin et al, 1997). Including these data as well as ours, initiator caspases which are inhibited by zVAD and AcYVAD-CHO, but not by Ac-DEVD-CHO may function upstream of mitochondrial damage.

Our observation of PARP cleavage without proteolysis of caspase-3 demonstrates the involvement of caspase-3-like proteases other than caspase-3 in the GC-mediated

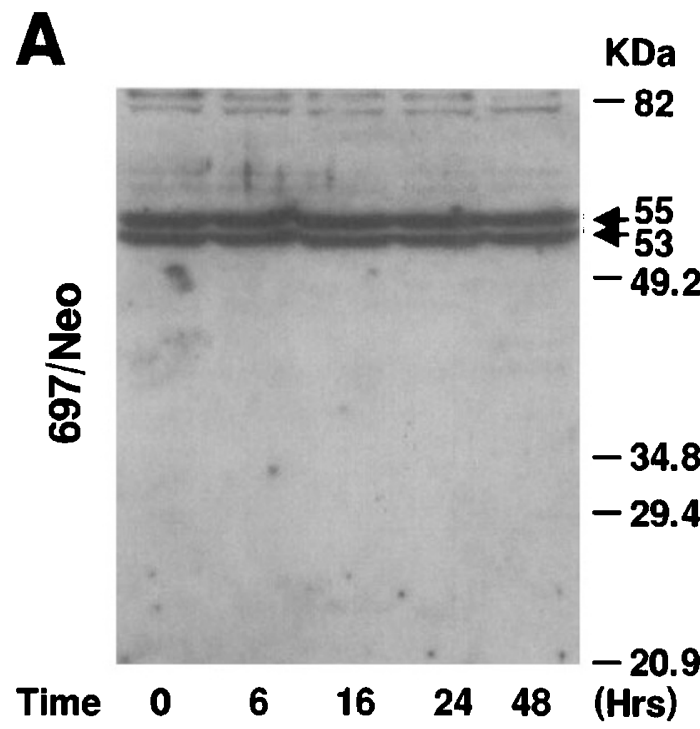

8
$\frac{8}{2}$
$\frac{1}{8}$

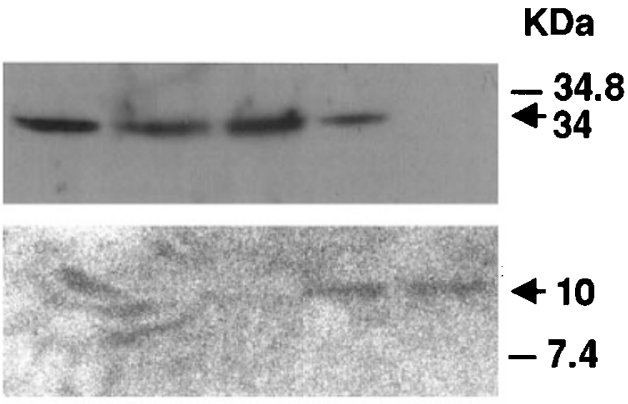

$\begin{array}{lllllll}\text { Time } & 0 & 6 & 16 & 24 & 48 & \text { (Hrs) }\end{array}$

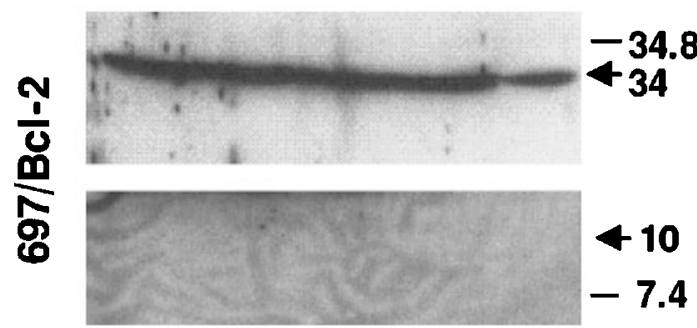

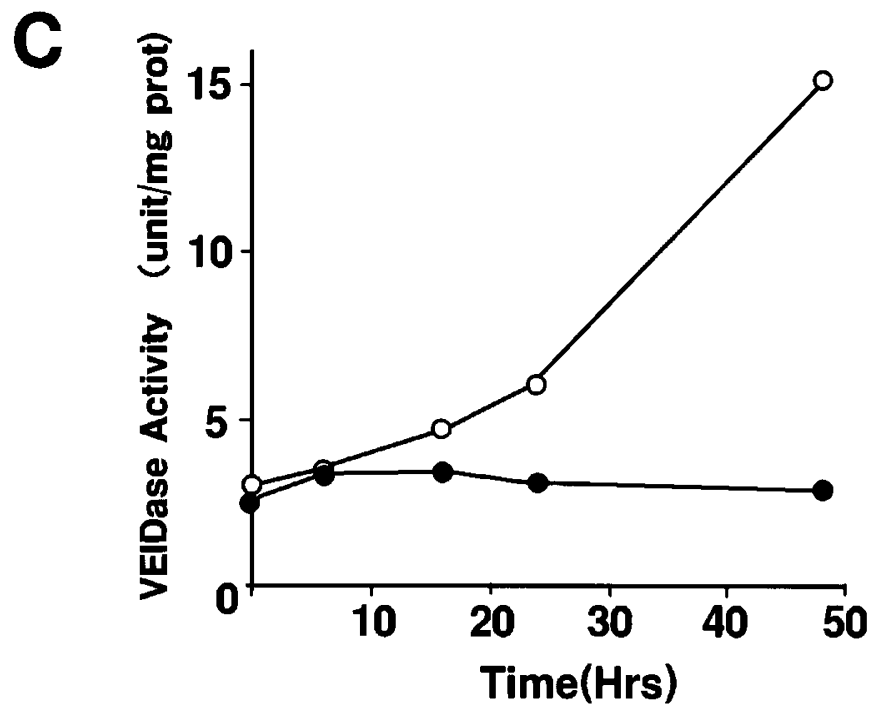

Figure 4 Activation of caspase- 6 but not caspase-8 during GC-induced apoptosis. 697-Neo and 697-Bcl-2 cells were treated with $10^{-7} \mathrm{M}$ of DEX. At various time points cells were harvested and cell lysates were subjected to SDS - PAGE, transferred to nitrocellulose and probed with anti-caspase-8 (A) or anti-caspase-6 (B) antibodies. (C) Cytosolic extracts were prepared from 697-Neo cells (open circles) and 697-Bcl-2 cells (closed circles) which were grown with $10^{-7} \mathrm{M}$ of DEX for various times. Caspase-6 activities in the lysates were determined using a fluorescent substrate Ac-VEID-MCA. One unit corresponds to the activity that cleaves $1 \mathrm{nmol}$ of the substrate at $37^{\circ} \mathrm{C}$ in $2 \mathrm{~h}$. Arrows indicate caspase-8/a (p55), caspase-8/b (p53), procaspase-6 (p34), and processed caspase-6 (p10) 
apoptotic process. This is in agreement with the finding that GC-mediated apoptosis is not impaired in the thymocytes of the mice deficient in caspase-3 (Kuida et al, 1996). Interestingly, the cleavage of PARP was still observed in thymocytes from caspase-3-deficient mice in the same situation. Furthermore, we showed the evidence that
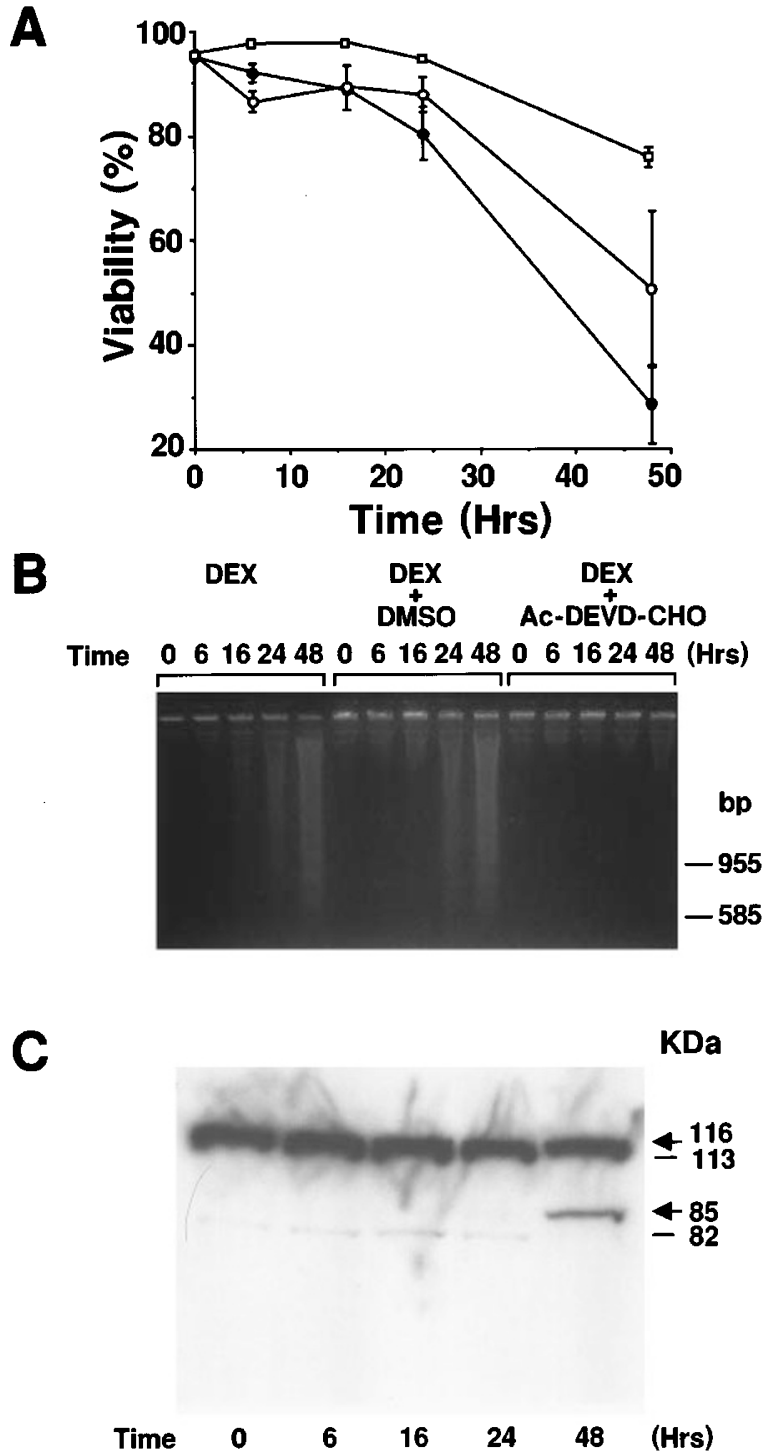

Figure 5 Inhibition of caspase-3-like proteases inhibits DNA fragmentation but not cell death. (A) 697-Neo cells were treated with $10^{-7} \mathrm{M}$ of DEX in the presence of dimethyl sulfoxide (DMSO) (closed circles), $100 \mu \mathrm{M}$ of Ac-DEVD$\mathrm{CHO}$ (open circles) or $100 \mu \mathrm{M}$ of zVAD-fmk (open squares). At indicated time points cells were collected, stained with $\mathrm{PI}$ and subjected to flowcytometry. All data represent mean $(n=3)$; bars, S.E.M. (B) 697-Neo cells were treated with $10^{-7} \mathrm{M}$ of DEX in the presence or absence of $100 \mu \mathrm{M}$ of Ac-DEVD-CHO. For some experiments, DMSO, a solvent of Ac-DEVD-CHO and ZVAD-fmk was added as a vehicle control. At various time points, $10^{6}$ cells were harvested and subjected to agarose gel electrophoresis. (C) 697-Neo cells were treated with $10^{-7} \mathrm{M}$ of DEX in the presence of $100 \mu \mathrm{M}$ of Ac-DEVD-CHO. At various time points cells were harvested and cell lysates were subjected to immunoblotting probed with anti-PARP antibody. Arrows indicate full length and processed PARP (p116 and p85, respectively) caspase- 6 is proteolytically activated during GC-induced apoptosis. Since caspase- 6 is reported to be another effector caspase in apoptotic cells (Faleiro et al, 1997), it is probable that caspase- 6 but not caspase- 3 contributes to GC-induced apoptosis. Activation of caspase- 6 was not restricted to a specific cell line because its proteolysis was also observed in T-cell leukemia line Jurkat treated with DEX (data not shown). However, since the substrate specificity of caspase- 6 is distinct from that of caspase-3 (VEHD vs DEVD) (Thornberry et al, 1997), it is still possible that other caspase-3-like proteases, such as caspase-7 (Mch3/ICE-LAP3/CMH-1) (Fernandes-Alnemri et al, 1995b; Duan et al, 1996; Lippke et al, 1996) or other unknown caspases, may play some role in apoptosis mediated by $\mathrm{GC}$, including the cleavage of PARP. At least a role for caspase-8, which has been shown to cleave PARP in vitro (Muzio et al, 1996), was excluded from our experiments.

Lastly, we demonstrated that a caspase-3 inhibitor, AcDEVD-CHO, efficiently inhibited DNA degradation to nucleosome-sized fragments, but merely delayed cell death as assessed by loss of plasma membrane integrity. In this regard, DNA fragmentation factor 45 (DFF45) and an inhibitor of caspase-activated deoxyribonuclease (ICAD) have been cloned recently (Liu et al, 1997; Enari et al, 1998). Mouse ICAD can be a counterpart of human DFF45. Caspase-mediated cleavage of ICAD is necessary to release active caspase-activated deoxyribonuclease (CAD). We thus speculate that, without the cleavage of ICAD/DFF45 in the presence Ac-DEVD-CHO, DNA fragmentation is not observed, while non-apoptotic cell death still occurs. Interestingly, it has also been shown that nuclear apoptosis, such as chromatin condensation, induced by either etoposide or Bax was inhibited by ZVAD-fmk, while necrotic cell death was not prevented (Hirsh et al, 1997; Xiang et al, 1996).

Various types of apoptotic signals have been shown to converge on the activation of caspases. However, our findings suggest the existence of 'private' cascade of caspase activation for each apoptotic stimulation.

\section{Materials and Methods}

\section{Cells and culture conditions}

697-Bcl-2 and 697-Neo lines are human pre-B leukemia 697 cells infected with recombinant $\mathrm{Bcl}-2$ retrovirus and control retrovirus, respectively (Miyashita and Reed, 1993). 697 cells were cultured in RPMI 1640 medium supplemented with $10 \%$ FBS, $50 \mathrm{U} / \mathrm{ml}$ penicillin and $0.1 \mathrm{mg} / \mathrm{ml}$ streptomycin. For some experiments, caspase inhibitors, Ac-DEVD-CHO and zVAD-fmk (Peptide Institute, Inc., Osaka, Japan) were added to the medium.

\section{Antibodies}

Recombinant caspase- 6 and caspase- 8 proteins were produced in bacteria and purified as His6-tagged fusion proteins using Ni-chelation affinity chromatography as described (Zhou et al, 1997). New Zealand white rabbits were immunized multiple times with $0.5 \mathrm{mg}$ doses of these recombinant proteins, delivered by subcutaneous injections in 
an aluminum-based adjuvant. The specificity of the resulting antisera for detection of caspase- 6 or -8 was confirmed by immunoblot analysis of recombinant purified caspases, showing reactivity with the intended caspases but not with caspases-1, 3, 7 or 10. Anti-PARP monoclonal antibody and anti-caspase-3 monoclonal antibody were purchased from Biomol and Transduction Laboratories, respectively.

\section{Cell viability and DNA fragmentation assays}

Cell viability was determined by flow-cytometric analysis of cells stained with $50 \mu \mathrm{g} / \mathrm{ml}$ of PI using a Becton-Dickinson FACSort. For DNA fragmentation assays, cells were recovered from cultures at various time points of DEX treatment and $10^{6}$ cells were analyzed by the gel-electrophoresis method described previously (Sorenson et al, 1990).

\section{Immunoblot analysis}

Protein detection with Western blot was performed as described previously (Miyashita et al, 1994). Briefly, $30 \mu \mathrm{g}$ (90 $\mu \mathrm{g}$ for caspase-6 detection) of the lysate were loaded onto SDS-PAGE gels. Resolved proteins were electrophoretically transferred to nitrocellulose membranes. Anti-PARP and anti-caspase- 3 monoclonal antibodies and anticaspase- 6 and anti-caspase- 8 polyclonal antibodies were used for primary antibodies. Horse radish peroxidase-conjugated goat anti-rabbit IgG (Sigma) and rabbit anti-mouse IgG (DAKO) were used as secondary antibodies, and proteins were visualized by ECL (Amersham).

\section{Detection of mitochondrial membrane potential $(\Delta \Psi \mathrm{m})$}

To detect $\Delta \Psi \mathrm{m}, \mathrm{DiOC}_{6}(3)$ (Molecular Probes) (dissolved in dimethylsulfoxide (DMSO) at $4 \mathrm{mM}$ ) was added to the cells $\left(5 \times 10^{5}\right)$ to make the final concentration of $40 \mathrm{nM}$. After $15 \mathrm{~min}$ of incubation in a $\mathrm{CO}_{2}$ incubator at $37^{\circ} \mathrm{C}$, cells were centrifuged and resuspended in PBS. Stained cells (10 000) were analyzed by a FACSort. Fluorescent cells were excited using a $488 \mathrm{~nm}$ argon-ion laser. Green fluorescence was monitored through a $530 / 20 \mathrm{~nm}$ band pass filter.

\section{Detection of ROS production}

Cells $\left(5 \times 10^{5}\right)$ were loaded with $5 \mu \mathrm{M}$ DCFH-DA (Molecular Probes) (dissolved in DMSO at $10 \mathrm{mM}$ ) for $1 \mathrm{~h}$ at $37^{\circ} \mathrm{C}$ in a $\mathrm{CO}_{2}$ incubator. Cells were then centrifuged and resuspended in PBS. Stained cells (10 000) were analyzed by a FACSort under the condition described above. In cytofluorometry, forward and side scatters were gated on the population of normal sized lymphocytes.

\section{Fluorometric measurement of proteolytic cleavage}

The fluorometric cleavage activities of 697 lysates were measured as described previously except that Ac-VEID-MCA and Ac-DEVD-MCA (Peptide Institute, Inc., Osaka, Japan) were used as fluorogenic substrates (Miyashita et al, 1997). The fluorescence of the cleaved substrate was determined using a spectrophotometer set at an excitation wavelength of $365 \mathrm{~nm}$ and an emission wavelength of $450 \mathrm{~nm}$.

\section{Acknowledgements}

We thank Dr Ryosuke Takahashi for helpful discussions. We are also grateful to Yuko Ohtsuka and Atsuko Asaka for technical assistance and
Kayoko Saito for manuscript preparation. This study was supported in part by grants for Pediatric Research and for Cancer Research from the Ministry of Health and Welfare, and Grant-in-Aid for Scientific Research from the Ministry of Education, Science and Culture, Japan and NIH grant CA72994.

\section{References}

Boldin MP, Goncharov TM, Goltsev YV and Wallach D (1996) Involvement of MACH, a novel MORT1/FADD-interacting protease, in Fas/APO-1- and TNF receptorinduced cell death. Cell 85: 803-815

Bossy-Wetzel E, Newmeyer DD and Green DR (1998) Mitochondrial cytochrome c release in apoptosis occurs upstream of DEVD-specific caspase activation and independently of mitochondrial transmembrane depolarization. EMBO J. 17: $37-49$

Duan H, Chinnaiyan AM, Hudson PL, Wing JP, He WW and Dixit VM (1996) ICELAP3, a novel mammalian homologue of the Caenorhabditis elegans cell death protein Ced-3 is activated during Fas- and tumor necrosis factor-induced apoptosis. J. Biol. Chem. 271: 1621-1625

Enari M, Sakahira H, Yokoyama H, Okawa K, Iwamatsu A and Nagata S (1998) A caspase-activated DNase that degrades DNA during apoptosis, and its inhibitor ICAD. Nature 391: 43-50

Faleiro L, Kobayashi R, Fearnhead H and Lazebnik Y (1997) Multiple species of CPP32 and Mch2 are the major active caspases presentin apoptotic cells. EMBO J. $16: 2271-2281$

Fernandes-Alnemri T, Litwack G and Alnemri ES (1994) CPP32, a novel human apoptotic protein with homology to Caenorhabditis elegans cell death protein Ced-3 and mammalian interleukin-1 $\beta$ - converting enzyme. J. Biol. Chem. 269: 30761-30764

Fernandes-Alnemri T, Litwack G and Alnemri ES (1995a) Mch2, a new member of the apoptotic Ced-3/lce cysteine protease gene family. Cancer Res. 55: $2737-2742$

Fernandes-Alnemri T, Takahashi A, Armstrong R, Krebs J, Fritz L, Tomaselli KJ, Wang L, Yu Z, Croce CM, Salveson G, Earnshaw WC, Litwack G and Alnemri ES (1995b) Mch3, a novel human apoptotic cysteine protease highly related to CPP32. Cancer Res. 55: 6045-6052

Fernandes-Alnemri T, Armstrong RC, Krebs J, Srinivasula SM, Wang L, Bullrich F, Fritz LC, Trapani JA, Tomaselli KJ, Litwack G and Alnemri ES (1996) In vitro activation of CPP32 and Mch3 by Mch4, a novel human apoptotic cysteine protease containing two FADD-like domains. Proc. Natl. Acad. Sci. USA 93: $7464-7469$

Hirata H, Takahashi A, Kobayashi S, Yonehara S, Sawai H, Okazaki T, Yamamoto K and Sasada M (1998) Caspases are activated in a branched protease cascade and control distinct downstream processes in Fas-induced apoptosis. J. Exp. Med. 187: 587-600

Hirsch T, Marchetti P, Susin SA, Dallaporta B, Zamzami N, Marzo I, Geuskens M and Kroemer G (1997) The apoptosis-necrosis paradox. Apoptogenic proteases activated after mitochondrial permeability transition determine the mode of cell death. Oncogene 15: 1573-1581

Hockenbery DM, Oltvai ZN, Yin XM, Milliman CL and Korsmeyer SJ (1993) $\mathrm{Bcl}-2$ functions in an antioxidant pathway to prevent apoptosis. Cell 75 : $241-251$

Kroemer G, Zamzami N and Susin SA (1997) Mitochondrial control of apoptosis. Immunol. Today. 18: 44-51

Kuida K, Zheng TS, Na S, Kuan C, Yang D, Karasuyama H, Rakic P and Flavell RA (1996) Decreased apoptosis in the brain and premature lethality in CPP32deficient mice. Nature 384: 368-372

Lippke JA, Gu Y, Sarnecki C, Caron PR and Su MS (1996) Identification and characterization of CPP32/Mch2 homolog 1 , a novel cysteine protease similar to CPP32. J. Biol. Chem. 271: 1825-1828

Liu X, Zou H, Slaughter C and Wang X (1997). DFF, a heterodimeric protein that functions downstream of caspase-3 to trigger DNA fragmentation during apoptosis. Cell 89: $175-184$

Miyashita T and Reed JC (1993) Bcl-2 oncoprotein blocks chemotherapy-induced apoptosis in a human leukemia cell line. Blood 81: 151-157

Miyashita T, Krajewski S, Krajewska M, Wang HG, Lin HK, Liebermann DA, Hoffman $B$ and Reed JC (1994) Tumor suppressor 553 is a regulator of bcl-2 and bax gene expression in vitro and in vivo. Oncogene 9: 1799-1805 
Miyashita T, MamiU, Inoue T, Reed JC and Yamada M (1997) Bcl-2 relieves the transrepressive function of the glucocorticoid receptor and inhibits the activation of CPP32-like cysteine proteases. Biochem. Biophys. Res. Commun. 233: 781 787

Muzio M, Chinnaiyan AM, Kischkel FC, O’Rourke K, Shevchenko A, Ni J, Scaffidi C, Bretz JD, Zhang M, Gentz R, Mann M, Krammer PH, Peter ME and Dixit VM (1996) FLICE, a novel FADD-homologous ICE/CED-3-like protease, is recruited to the CD95 (Fas/APO-1) death-inducing signaling complex. Cell 85: 817-827

Nicholson DW, Ali A, Thornberry NA, Vaillancourt JP, Ding CK, Gallant M, Gareau Y, Griffin PR, Labelle M, Lazebnik YA, Munday NA, Raju SM, Smulson ME, Yamin TT, Yu VL and Miller DK (1995) Identification and inhibition of the ICE/CED-3 protease necessary for mammalian apoptosis. Nature 376: $37-43$

Petit PX, O'Connor JE, Grunwald D and Brown SC (1990) Analysis of the membrane potential of rat- and mouse-liver mitochondria by flow cytometry and possible applications. Eur. J. Biochem. 194: 389-397

Salvesen GS and Dixit VM (1997) Caspases: intracellular signaling by proteolysis Cell 91: 443-446

Scaffidi C, Medema JP, Krammer PH and Peter ME (1997) FLICE is predominantly expressed as two functionally active isoforms, caspase-8/a and caspase-8/b. J. Biol. Chem. 272: 26953-26958

Sorenson CM, Barry MA and Eastman A (1990) Analysis of events associated with cell cycle arrest at G2 phase and cell death induced by cisplatin. J. Natl. Cancer Inst. 82: 749-755
Susin SA, Zamzami N, Castedo M, Daugas E, Wang HG, Geley S, Fassy F, Reed JC and Kroemer G (1997) The central executioner of apoptosis: multiple connections between protease activation and mitochondria in Fas/APO-1/ CD95- and ceramide-induced apoptosis. J. Exp. Med. 186: 25-37

Tewari M, Quan LT, O'Rourke K, Desnoyers S, Zeng Z, Beidler DR, Poirier GG, Salvesen GS and Dixit VM (1995) Yama/CPP32 beta, a mammalian homolog of CED-3, is a CrmA-inhibitable protease that cleaves the death substrate poly(ADP-ribose) polymerase. Cell 81: 801-809

Thornberry NA, Rano TA, Peterson EP, Rasper DM, Timkey T, Garcia-Calvo M Houtzager VM, Nordstrom PA, Roy S, Vaillancourt JP, Chapman KT and Nicholson DW (1997) A combinatorial approach defines specificities of members of the caspase family and granzyme B. Functional relationships established for key mediators of apoptosis. J. Biol. Chem. 272: 17907-17911

Xiang J, Chao DT and Korsmeyer SJ (1996) BAX-induced cell death may not require interleukin $1 \beta$-converting enzyme-like proteases. Proc. Natl. Acad. Sci. USA 93 $14559-14563$

Zamzami N, Marchetti P, Castedo M, Decaudin D, Macho A, Hirsch T, Susin SA, Petit PX, Mignotte B and Kroemer G (1995) Sequential reduction of mitochondria transmembrane potential and generation of reactive oxygen species in early programmed cell death. J. Exp. Med. 182: 367-377

Zhou Q, Snipas S, Orth K, Muzio M, Dixit VM and Salvesen GS (1997) Target protease specificity of the viral serpin $\mathrm{CrmA}$. Analysis of five caspases. J. Biol Chem. 272: $7797-7800$ 